\title{
Calculating Evacuation Times from Lecture Theatre Type Rooms Using a Network Model
}

\author{
MICHAEL SPEARPOINT ${ }^{1}$, and XIAOXING XIANG ${ }^{2}$ \\ ${ }^{1}$ Department of Civil and Natural Resources Engineering \\ University of Canterbury \\ Private Bag 4800, Christchurch, 8020, New Zealand \\ ${ }^{2}$ WSP Lincolne Scott \\ 246 Bourke Street, Melbourne, Victoria, Australia
}

\begin{abstract}
This paper presents a series of trial evacuations from several university campus lecture theatres. The results from the trial evacuations are compared against simulations using a Monte Carlo network evacuation model. Data from a number of literature sources from lecture theatre type rooms is then used to further compare the predictions from the model. Results show that the model gives reasonable predictions when the constrictions provided by either the exit doors or the aisle widths are accounted for. The inclusion in the model of a reduction in maximum movement speed due to the rows of seats is found to give a general overprediction.
\end{abstract}

KEYWORDS: evacuation, networks, modelling, auditoria.

\section{INTRODUCTION}

Fire engineering design often requires the calculation of evacuation times from buildings. A range of methods are available from simple hand calculations through to complex numerical models. These calculation methods need to be validated against a wide range of data where trial evacuations provide useful sources. There are a considerable number of evacuation models available [1] of varying types and complexity which can range from node/arc type models such as EVACNET+ to 'agent-based' fine network models such as buildingEXODUS, ASERI, etc. and continuous models such as Simulex. Each type of model has certain strengths and weaknesses which include requirements on the level of detail needed as input, the capability of the numerical algorithms, the level of detail provided as output, the speed of the simulations etc. Work has been ongoing at the University of Canterbury to develop a Monte Carlo network evacuation model (called EvacuatioNZ) that allows for a large number of simulations to be rapidly undertaken where many characteristics of the simulations can be represented by statistical distributions. In order to develop and validate the model it is beneficial to examine the performance of individual components.

A lecture theatre style room includes lecture theatres, auditoria, cinemas, indoor sports stadia etc. These rooms have particular features such as: rows of seats that may be fixed or pivoted; one or more aisles which may be fixed or variable width; have sloped, stepped or flat floors (and combinations of two or all three); single or multiple exits which might be different sizes and at different locations; variable occupant loads and a range of occupant characteristics. Predtechenskii and Milinskii [2] note evacuation from these spaces is complex in itself and thus difficult to compute. Movement speeds will be affected by the occupant characteristics and the occupant density; exhibit one or more merging flows as occupants exit the space and may be slowed by the features in the space such as the rows of seats, the floor configuration and the widths of the aisles. In terms of the potential for people to be slowed by the rows of seats, Predtechenskii and Milinskii give a maximum movement speed along rows of $0.45 \mathrm{~m} / \mathrm{s}$ in summer dress. Alternatively Li and Chow [3] used $0.60 \mathrm{~m} / \mathrm{s}$ (compared with $1.30 \mathrm{~m} / \mathrm{s}$ free walking) in their numerical study and Gwynne et al. [4] used 1.08 to $1.35 \mathrm{~m} / \mathrm{s}$ (compared with 1.20 to $1.50 \mathrm{~m} / \mathrm{s}$ free walking speed) in their numerical study.

The question then arises how should lecture theatre style rooms be represented in a network type model such as EvacuatioNZ? Is it appropriate to use nodes that do not include any specific characteristics and if not, what is needed? This paper presents details of a series of trial evacuations from lecture theatres and data from additional trials carried out at the University of Canterbury plus data from various sources in the literature. The trial evacuation data is compared with EvacuatioNZ predictions using several different 
methods to represent a lecture theatre type room to determine whether these spaces can be reasonably simulated in the model.

\section{PRIMARY TRIAL EVACUATIONS}

New Zealand regulations [5] require certain buildings to have emergency evacuation plans which typically result in trial evacuations being carried out on a regular basis during normal working hours. A series of unannounced trial evacuations in eight of the largest lecture rooms on the University of Canterbury campus is described below (Table 1) and more details are available in the work by Xiang [6].

The Arts (A) lecture theatre block is a single-story building comprising of three lecture rooms. The rooms are combined with a foyer which is connected to the outside by four final exits at ground level. Each lecture room has a main double door exit at the front and there is also an alternative exit at the back of each room connected via stairs to a final exit at ground level that is separate from the main foyer. In rooms A2 and A3 the rear alternative exit is limited by the stair width of $1.05 \mathrm{~m}$. Lecture room A1 also has a third double door means of evacuation at the front of the lecture room which leads to the outside through a small anteroom. The rear exit of A1 has a $0.85 \mathrm{~m}$ wide door at the top of the stairs.

The Central (C) lecture theatre block is a single-storey structure with an intermediate floor. It consists of three large lecture rooms with evacuation routes to final exits at both ground floor and intermediate floor levels. On the ground level, two main entrances located at the left and right-hand sides of the building are connected to the outside. There are two $1.45 \mathrm{~m}$ wide double door entrances at the front of lecture room $\mathrm{C} 1$ and a $1.45 \mathrm{~m}$ wide double door entrance at the front of lecture rooms $\mathrm{C} 2$ and $\mathrm{C} 3$ on the ground level linked to a foyer space. On the intermediate floor, the back exit from each lecture room links to two final exits to the outside through a passage. The occupant capacity for of the lecture rooms in this block is 800 people.

The Science (S) lecture theatre block is a multiple level building with a total of 11 different-sized lecture and tutorial rooms. Two of the largest sized lecture rooms on the first floor were selected for the trials. On the ground floor, four final exits are located on each side of the building, one main entrance and three fire exits. Four stairs link to the first floor where four lecture rooms S1 to S4 are in a central space. Each room has two exits, one $1.40 \mathrm{~m}$ wide double door at the front and the other $0.90 \mathrm{~m}$ wide single door midway up the room connected to an upper level by a stair as the room inclines from front to back. The Science lecture theatre block can potentially accommodate about 1000 occupants.

Table 1. Primary trial evacuation building geometry and occupant use.

\begin{tabular}{|c|c|c|c|c|c|c|}
\hline $\begin{array}{c}\begin{array}{c}\text { Lecture } \\
\text { room }\end{array} \\
\text { rom }\end{array}$ & $\begin{array}{c}\text { Dimensions } \\
(\mathbf{m})\end{array}$ & $\begin{array}{c}\text { Aisle } \\
\text { width } \\
\text { (m) }\end{array}$ & $\begin{array}{c}\text { Occupant } \\
\text { capacity }\end{array}$ & $\begin{array}{c}\text { Exits (main listed } \\
\text { first) and width } \\
(\mathrm{m})\end{array}$ & $\begin{array}{l}\text { Number } \\
\text { of users }\end{array}$ & $\begin{array}{c}\text { Total } \\
\text { clearance time } \\
(\mathbf{s})\end{array}$ \\
\hline A1 & $20 \times 16$ & 1.00 & 384 & $\begin{array}{c}\text { Front, } 1.65 \mathrm{~m} \\
\text { Side, } 1.65 \mathrm{~m} \\
\text { Rear }, 0.85 \mathrm{~m}\end{array}$ & $\begin{array}{c}105 \\
78 \\
63\end{array}$ & 114 \\
\hline A 2 & $15 \times 11$ & 1.05 & 200 & $\begin{array}{c}\text { Front, } 1.80 \mathrm{~m} \\
\text { Rear. } 1.05 \mathrm{~m}\end{array}$ & $\begin{array}{c}122 \\
49\end{array}$ & 101 \\
\hline A3 & $12 \times 10$ & 1.30 & 140 & $\begin{array}{l}\text { Front, } 1.80 \mathrm{~m} \\
\text { Rear, } 1.05 \mathrm{~m}\end{array}$ & $\begin{array}{c}95 \\
1\end{array}$ & 84 \\
\hline $\mathrm{C} 1$ & $20 \times 19$ & 1.40 & 400 & $\begin{array}{c}\text { Front right, } 1.45 \mathrm{~m} \\
\text { Front left, } 1.45 \mathrm{~m} \\
\text { Rear right, } 0.74 \mathrm{~m} \\
\text { Rear left, } 0.74 \mathrm{~m}\end{array}$ & $\begin{array}{l}66 \\
54 \\
38 \\
34 \\
\end{array}$ & 96 \\
\hline $\mathrm{C} 2$ & $17 \times 15$ & 1.40 & 200 & $\begin{array}{l}\text { Front, } 1.45 \mathrm{~m} \\
\text { Rear, } 0.74 \mathrm{~m}\end{array}$ & $\begin{array}{c}155 \\
31\end{array}$ & 117 \\
\hline $\mathrm{C} 3$ & $17 \times 15$ & 1.40 & 200 & $\begin{array}{l}\text { Front, } 1.45 \mathrm{~m} \\
\text { Back, } 0.74 \mathrm{~m}\end{array}$ & $\begin{array}{c}53 \\
8 \\
\end{array}$ & 73 \\
\hline S2 & $13 \times 12$ & 1.18 & 253 & $\begin{array}{c}\text { Front, } 1.45 \mathrm{~m} \\
\text { Midway, } 0.97 \mathrm{~m}\end{array}$ & $\begin{array}{l}56 \\
44\end{array}$ & 77 \\
\hline S4 & $15 \times 12$ & 1.18 & 209 & $\begin{array}{c}\text { Front, } 1.45 \mathrm{~m} \\
\text { Midway, } 0.97 \mathrm{~m}\end{array}$ & $\begin{array}{l}63 \\
63\end{array}$ & 91 \\
\hline
\end{tabular}


All lecture theatres are equipped with a siren type evacuation alarm, an emergency lighting system and illuminated exit signs. The Science lecture block also has a pre-recorded public address system used to provide a voice message containing evacuation instructions combined with a continuous alarm signal.

\section{Participants}

The majority of occupants were students in their late teens to early twenties and there was a relatively even gender mix although exact proportions were not recorded. A very small proportion of the evacuees were staff of varying ages. It is presumed that the whole population was familiar with the building as they were full-time students using the lecture room for regular classes. Since trial evacuations are conducted throughout campus every six months, it is also presumed that occupants have participated in similar trials before so that they are aware of the evacuation procedure and more likely to start evacuation without much delay.

\section{Observations}

Observers were appointed to record the number of people exiting from an exit using a hand-held data logger. During the trial evacuation they were positioned outside of the room, near each exit but did not interfere with the flow from the doorway. Occupant movement in lecture rooms was also recorded by video cameras. Due to equipment and personnel limitations only lecture rooms A1, C1 and S4 were recorded. In order to have a good view of the entire auditorium area, cameras were set up in separate projection rooms at the rear of the lecture rooms where possible. This location provided a high level position so that the cameras had a view over the whole room and was unlikely to be noticed by the occupants.

According to the images captured during the trial, there were 187 and 119 people recorded by the cameras in $\mathrm{A} 1$ and $\mathrm{C} 1$ respectively. Some people in the front were not distinguishable or were blocked by the people sat behind them. However, the proportion of the identified people was sufficient to identify $76 \%$ of the people in $\mathrm{A} 1$ and $62 \%$ of the people in $\mathrm{C} 1$.

\section{Pre-movement Behaviour}

During the trial it was difficult to identify the point at which the whole group of students reached a standing position as the time taken by each individual to make decisions varied. It was easier to identify people when they were sitting in the class but once people started to move and stand up they created an increasing number of blockages in front of the camera. Some students were already going through a door whereas others were still packing up their belongings in the middle of rows. However it was possible to determine from the video images when people at each end of a row had stood up and were preparing to move into the aisle while the majority of the occupants in the middle of rows (from $74 \%$ to $76 \%$ of the population) had packed up their belongings. This situation was taken to be representative of the pre-movement time and was $14 \mathrm{~s}$ for $\mathrm{A} 1$ and $22 \mathrm{~s}$ for $\mathrm{C} 1$. From the observations it was noted that the pre-movement time in A1 was less than $\mathrm{C} 1$ because of the clear instructions given by the lecturer.

\section{SECONDARY TRIAL EVACUTIONS}

Additional trial evacuation data using students has been collected over several years by the primary author. In all cases specific instructions were given to the occupants so that they were aware of the purpose of the trial. This may have caused the occupants to not have taken the trial as seriously as a 'real' drill or may have led them to try and exit quicker than they may have done as if it was unannounced. Typically students were 19-20 years old and predominantly male. Table 2 gives details of the lecture rooms and total evacuation times from these trial evacuations. Where more than one exit was available then the number of people using each was noted. Room E10 and E14 had fixed continuous desks and fixed pivoted seats whereas rooms C112 and E15 had individual moveable desks and chairs. The desks in room C112 were sufficiently separate so as not to constrict the movement of people.

The trials in lecture room E17 involved 27 people ( 9 female, 18 male) with a wider age range (average was around 25 years) than the other secondary trials discussed above. The room furniture consisted of individual moveable desks and chairs rather than fixed rows of seats and the desks effectively created a $0.60 \mathrm{~m}$ wide constriction similar to an aisle. Two trials were conducted, one had no pre-movement time and the second had the occupants begin to exit according to a pre-determined log-normal distribution with a 
mean of $20 \mathrm{~s}$ and a standard deviation of $10 \mathrm{~s}$. To investigate whether the presence of the desks and chairs had any effect, the two trials were re-run without the desks and chairs in place and it was found that total evacuation times were only $1 \mathrm{~s}$ longer than the corresponding previous trial.

Table 2. Lecture room dimensions and occupant numbers for secondary trial evacuations.

\begin{tabular}{|c|c|c|c|c|c|c|}
\hline Room & $\begin{array}{c}\underset{\text { size }}{\text { Approx. }} \\
\text { (m) }\end{array}$ & $\begin{array}{l}\text { Exit number } \\
\text { and width/s }\end{array}$ & $\begin{array}{r}\begin{array}{c}\text { Aisle } \\
\text { width }\end{array} \\
\text { (m) }\end{array}$ & Occupants & $\begin{array}{c}\text { Total } \\
\text { evacuation } \\
\text { time } \\
(\mathbf{s}) \\
\end{array}$ & Other comments \\
\hline \multirow[t]{2}{*}{ E10 } & \multirow{2}{*}{$\begin{array}{c}10.0 \times \\
6.5\end{array}$} & \multirow{2}{*}{$\begin{array}{l}2 \times 0.78 \mathrm{~m} \\
\text { doors }\end{array}$} & \multirow[t]{2}{*}{1.00} & 24 & 22 & $\begin{array}{l}1 / 3 \text { to } 2 / 3 \text { split } \\
\text { between doors }\end{array}$ \\
\hline & & & & 26 & 30 & All used one door \\
\hline \multirow{2}{*}{ E15 } & \multirow{2}{*}{$7.0 \times 5.0$} & \multirow{2}{*}{$1 \times 0.78 \mathrm{~m}$ door } & 1.00 & 8 & 15 & - \\
\hline & & & 0.50 & 16 & (see Table 4) & (see text) \\
\hline \multirow{2}{*}{ E14 } & \multirow{2}{*}{$6.0 \times 9.0$} & \multirow{2}{*}{$\begin{array}{l}1 \times 0.78 \mathrm{~m} \text { door } \\
1 \times 1.38 \mathrm{~m} \text { door }\end{array}$} & \multirow{2}{*}{0.78} & 21 & 17 & $\begin{array}{l}9 \text { occupants used } \\
1.38 \text { m wide door }\end{array}$ \\
\hline & & & & 34 & 26 & $\begin{array}{l}22 \text { occupants used } \\
1.38 \mathrm{~m} \text { wide door }\end{array}$ \\
\hline E17 & $7.9 \times 5.2$ & $1 \times 0.78 \mathrm{~m}$ door & 0.60 & 27 & (see Table 4) & (see text) \\
\hline C112 & $9.0 \times 8.0$ & $1 \times 0.89 \mathrm{~m}$ door & (see text) & 14 & 20 & - \\
\hline
\end{tabular}

Similar to the trials conducted in E17, a series of trials in lecture room E15 were conducted involving 16 people ( 1 female, 15 male) with a similar average age of 25 years. The room furniture created a $0.50 \mathrm{~m}$ wide constriction similar to an aisle. Three trials were conducted, one had no pre-movement time, one had the occupants begin to exit according to a pre-determined log-normal distribution with mean $20 \mathrm{~s}$ and standard deviation of $10 \mathrm{~s}$ and one had the occupants begin to exit according to a pre-determined normal distribution again with a mean of $20 \mathrm{~s}$ and a standard deviation of $10 \mathrm{~s}$.

\section{LITERATURE DATA}

A number of studies have been identified in the literature that provide potentially useful information that can be used to examine the performance of the EvacuatioNZ model. In some studies the authors also carried out simulations using a range of available models. A short description of each study is given below.

Regan [7] recorded data from an earlier unannounced trial evacuation at the University of Canterbury. The trial utilised the same two $\mathrm{C} 1$ and $\mathrm{C} 2$ lecture theatres as discussed above. A total of 278 under-graduate students took part in the trial but the specific number of people in each theatre and the proportion of people using each exit were not given. Pre-movement times were recorded for a small group of individuals in each trial and the total evacuation time was $90 \mathrm{~s}$ although clearance times of each theatre were not given. The pre-movement statistics given by Regan [7] for $\mathrm{C} 1$ were a minimum of $14 \mathrm{~s}$, a median of $30 \mathrm{~s}$ and maximum of $76 \mathrm{~s}$. For $\mathrm{C} 2$ the statistics were a minimum of $9 \mathrm{~s}$, a median of $23 \mathrm{~s}$ and maximum of $60 \mathrm{~s}$. Olsson and Regan [8] subsequently modelled these two trials using Simulex.

Kimura and Sime [9] provide information on unannounced evacuation trials from two different lecture rooms. All of the participants were 18-19 years old but no details on movement speeds, gender, etc. were provided. Unfortunately details regarding the pre-movement time are sparse other than when the staff member told occupants to leave the room. Both rooms had two doors and an aisle width of $0.65 \mathrm{~m}$. The F lecture room dimensions were $10.47 \mathrm{~m}$ by $8.56 \mathrm{~m}$ and had doors at the two opposite sides of the back of the room which consisted of a $0.80 \mathrm{~m}$ wide entrance and a $0.76 \mathrm{~m}$ wide fire exit. The trial involved 56 people in which $55 \%$ used the entrance and the total evacuation time was $181 \mathrm{~s}$. The R lecture room had the same dimensions as the $\mathrm{F}$ lecture room but had a $1.30 \mathrm{~m}$ wide entrance at the back and a $0.76 \mathrm{~m}$ wide fire exit at the front. In this trial 77 people used the fire exit as directed by the staff member and the total evacuation time was $88 \mathrm{~s}$. It is somewhat surprising to note that the trial with more people using only the one exit had a much quicker total evacuation time although Kimura and Sime do not discuss this aspect. 
$\mathrm{Li}$ and Chow [3] give the results of a single trial evacuation from a $10.5 \mathrm{~m}$ by $15.0 \mathrm{~m}$ lecture room which had a $1.8 \mathrm{~m}$ wide aisle at each end of the rows of seats. The room had four exits but the trial only used a single $0.90 \mathrm{~m}$ wide exit. The trial involved 82 students with a total evacuation time of $66.5 \mathrm{~s}$.

Weckman et al. [10] report an unannounced trial evacuation of 612 occupants from a theatre in Finland during a play. There is limited geometrical detail and pre-movement information provided in the reference however the sequence of events relevant to this study are given in Table 3. Weckman et al. conducted modelling exercises using EVACNET+, Simulex, buildingEXODUS and ASERI but did not report the times at which the last person was determined to leave the auditorium. They suggested pre-movement time of $0-30 \mathrm{~s}$ gave the best representation of the exercise although did not say how that distribution was to be represented.

Table 3. Sequence of events for the Finnish theatre trial evacuation (adapted from Ref. [9]).

\begin{tabular}{|l|l|}
\hline Time (min:s) & Event \\
\hline $0: 00$ & Fire alarm started (bell outside but could not be heard by audience) \\
\hline $0: 25$ & Audience applauds - first person starts to leave \\
\hline $0: 30-0: 47$ & Tens (over one hundred?) people started to leave \\
\hline $0: 47$ & First announcement to evacuate \\
\hline $1: 06$ & Second announcement \\
\hline $3: 37$ & Last person leaves auditorium \\
\hline
\end{tabular}

Gwynne et al. [4] cite a series of evacuation trials from an auditorium at the 1985 Tsubuka pavilion. They carried out comparisons between the evacuation trials and buildingEXODUS although they noted that "data was lacking in several areas". The auditorium had a capacity of 500 people although the number occupants present in each drill was not known to Gwynne et al. Geometrical details regarding the auditorium were also unclear to Gwynne et al. other than the trials used one $3.6 \mathrm{~m}$ wide exit door used (of seven doors available). Four evacuation drills were undertaken with the total times given as 160,152, 166 and $157 \mathrm{~s}$ but no pre-movement data was given. Of particular note was that the evacuation times were affected by poor weather conditions on the far side of the exit.

Zhang et al. [11] describe an evacuation drill of 60 students from a lecture room with dimensions $7.1 \mathrm{~m}$ by $6.5 \mathrm{~m}$ with a single door and a single central aisle both $1.1 \mathrm{~m}$ wide. The exact position, pre-movement time and exit time of each occupant recorded and the total evacuation time was $37 \mathrm{~s}$. Zhang et al. simulated the trial using an agent-based multi-grid model considering a number of different scenarios.

\section{SIMULATION MODEL}

\section{Background}

The EvacuatioNZ model uses a coarse network approach to represent a building to reduce computational times allowing for many repeat runs to be completed in a relatively short time. Building spaces are described by a network of nodes which are connected together by paths. Nodes are defined in terms of length and width dimensions and connections are defined in terms of their length and other characteristics. A network has to have one or more 'safe' nodes which represent final destinations for people. Simulations are run over a defined time period or until all occupants had reached a 'safe' node. The simulation is broken into user specified time steps typically of 0.5 or $1 \mathrm{~s}$ duration.

People are represented as individuals with their own behavioural and personal attributes. The model includes a range of exit behaviour strategies including those that require the minimum travel distance to a 'safe' node, those that are preferred by the building users and those routes that are designated as fire exit paths. The choice of exit behaviour can be probabilistically assigned to groups of occupants and some ability to re-evaluate the choice during a simulation is included in the model by allowing occupants to fix their exit behaviour at the start of a simulation or re-select an exit behaviour as they enter a new node. Preevacuation times can be modelled through the use of distributions with the shape and statistics appropriately selected by the user. 
Movement in crowded conditions is based on the equations provided by Gwynne and Rosenbaum [12] such that the relationship between speed of travel and occupant density is given by a linearly decreasing function for occupant densities greater than 0.5 occupants $/ \mathrm{m}^{2}$. Baseline uncongested movement speeds can be fixed by the user or determined by the use of a distribution. The model also accounts for the effect of queues at constrictions using the effective width concept [13] where a $0.15 \mathrm{~m}$ boundary is used for doors and $0 \mathrm{~m}$ is used for aisles. The formation of a queue will depend on the presentation rate at the constriction and it is possible that no queue will form. Where a queue does form a person's movement speed is recalculated each time step so that the time to negotiate a constriction will vary during a simulation. A person can only move through a constriction into a path if the occupant density in the downstream node is less than a maximum occupant density specified in the model. The model has the ability to employ a range of distribution shapes whenever a statistical distribution can be specified for an input parameter and these distributions can be truncated at a specified upper and/or lower limit.

Previous published work has examined the performance of the basic model components [14] and has applied the model to a case study building [15]. To create a functional relationship between gender, age and walking speed this work used Ando et al.'s data (as cited by Smith [16]) as the starting point. Ando et al.'s data does not include any variability in the walking speed so the distributions for speed given by Lord et al. [17] were applied to the Ando et al. data (Fig. 1). It is recognised that the Lord et al. [17] data is only specified for three broad age bands and mean values somewhat differ from Ando et al. but is sufficient for this research to give maximum and minimum limits for free walking speeds.

A number of general assumptions are made for the simulations as a result of a lack of specific information or because of limitations of the model. Unless otherwise known it is assumed than the occupants were split 50/50 male and female. Rooms are assumed to be flat with a rectilinear geometry. The maximum movement speed of occupants depends on the age and gender of each individual but the actual movement speed depends on crowd density and the effect of any constrictions. Occupants are randomly distributed within the space at the start of a simulation with a maximum travel distance set as the sum of the linear length and width dimensions of the room. Where multiple exits were involved the model is configured to represent the original use such that the probability of an exit choice was specified as the proportion cited in the particular study.

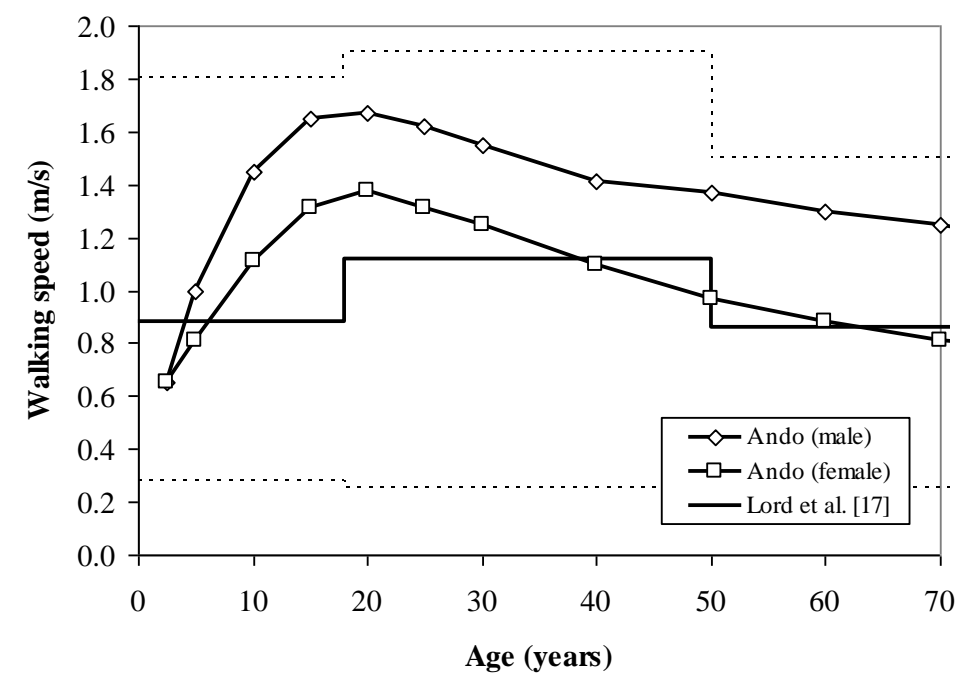

Fig. 1. Comparison of walking speed as a function of gender and age from an adaptation of Ando et al. with mean, maximum and minimum range values (dashed lines) from Lord et al. [17].

Base case simulations use an EvacuatioNZ room that has no specific characteristics defined. Three modifications are considered for lecture rooms where flow rates through exits are constricted by door or aisle widths depending on which effective width is narrower, an over-ride on maximum movement speed to account for the rows of seating and where both the aisle constriction and the rows of seating have an effect. For the purposes of the simulations described here the $0.45 \mathrm{~m} / \mathrm{s}$ taken from Predtechenskii and Milinskii [2] was used to set a maximum movement speed where the rows of seats were accounted for. 


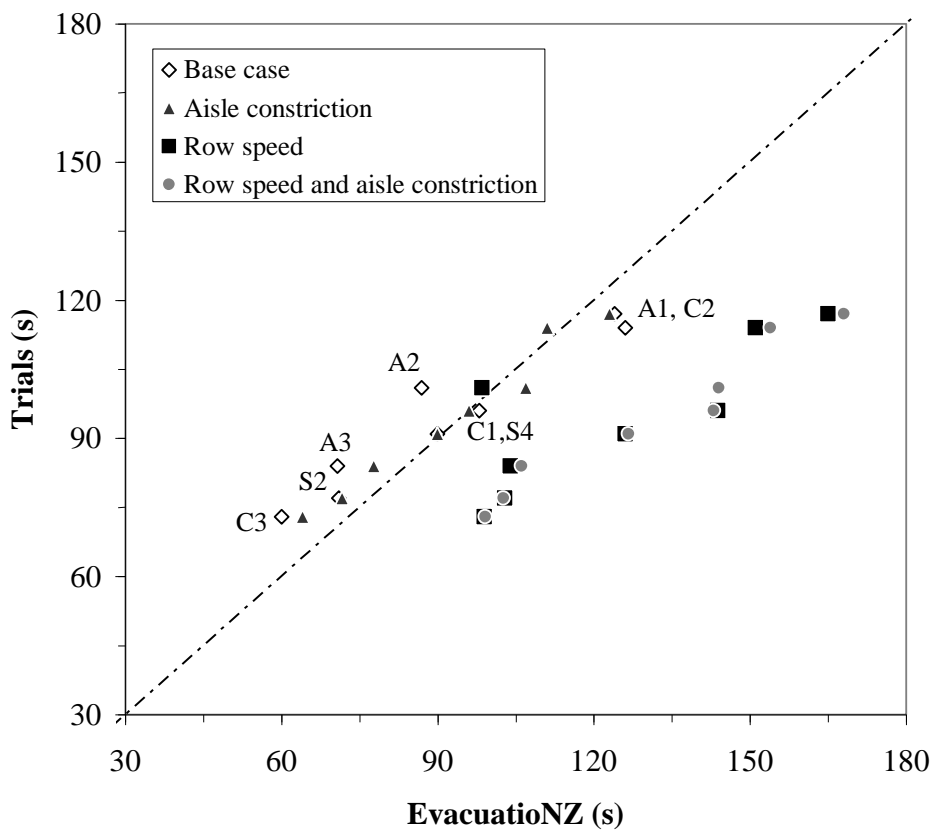

Fig. 2. Mean total evacuation times given by EvacuatioNZ for the four modelling approaches against the primary evacuation trial data.

EvacuatioNZ calculates a running average of the simulated total evacuation times and the user can make the model terminate when the total evacuation time of the current simulation changes the average by less than a specified convergence value. It is found that 100 to 500 simulations for each case give representative results such that the change in total evacuation time converged to $0.0005 \%$ or less. For example, modelling the Weckman et al. [10] Finnish theatre scenario which had the greatest number of occupants, requires 110 simulations to converge and takes a total $55 \mathrm{~s}$ on a dual core $2.4 \mathrm{GHz}$ PC. All total evacuation times are stated as the mean value plus or minus one standard deviation.

\section{Primary and Secondary Evacuation Data}

Since pre-movement times were only specifically determined for lecture rooms A1 and C1, an average of these two $(18 \mathrm{~s})$ was assumed for the pre-movement time for the other lecture rooms in order to model the primary evacuation trials. Figure 2 shows the mean total evacuation time from EvacuatioNZ for the four modelling approaches against the primary evacuation trial data. It can be seen that times from the base cases or the cases that included the effect of the aisles are very similar to each other and are slightly faster than the trial data. Where the model has included the reduction in the maximum movement speed due to the rows of seats the simulations generally over-predict by a significant margin regardless of whether the aisle constriction is included or not.

Flows through each exit were recorded in the primary trials and Fig. 3 compares the trial data with the range of maximum and minimum values obtained from the EvacuatioNZ simulations. The figure shows the effect of aisle constriction and where the number of people using each exit has been fixed to that recorded in the trial. 


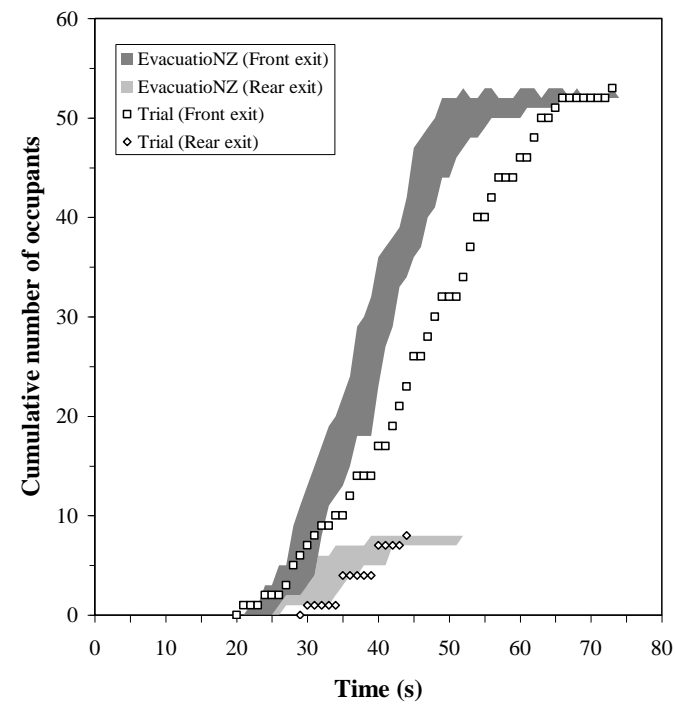

(a)

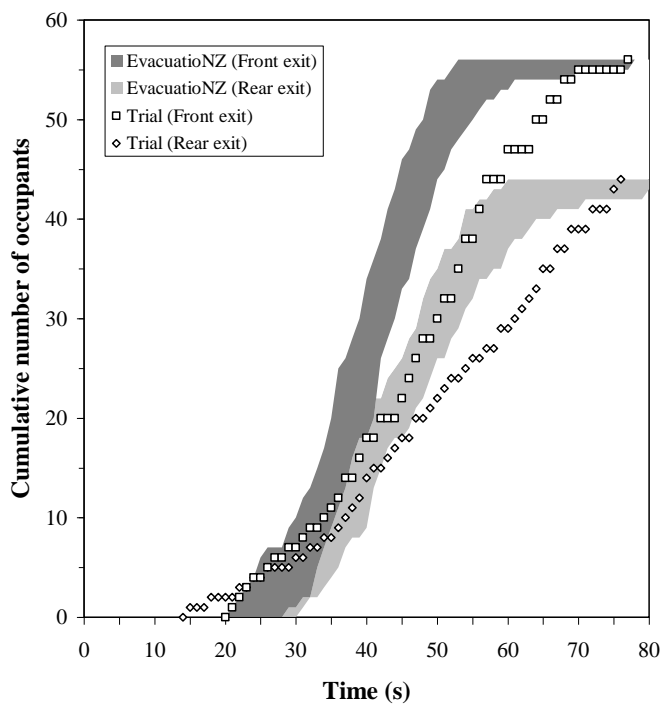

(c)

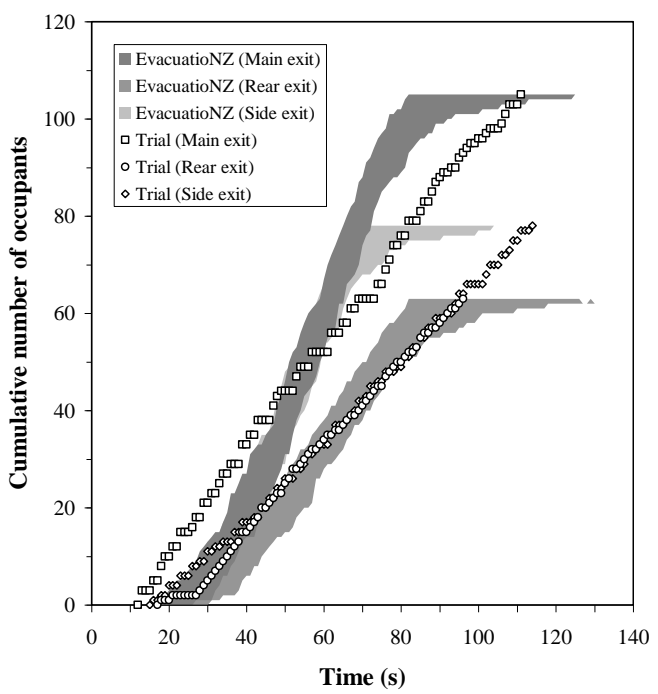

(b)

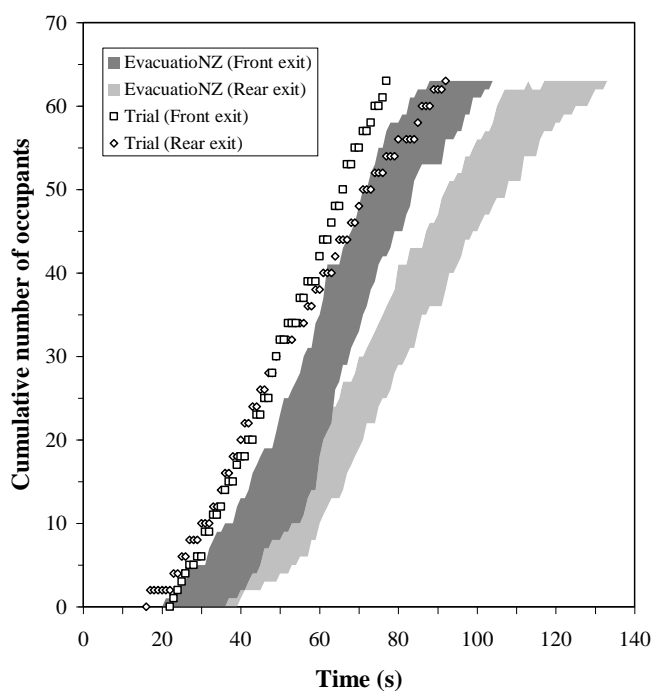

(d)

Fig. 3. Measured and simulated exit flows: (a) lecture room C3; (b) lecture room A1;

(c) lecture room $\mathrm{S} 2$; (d) lecture room $\mathrm{S} 4$.

Table 4 gives the lecture room E17 and E15 trial evacuation times compared with the EvacuationZ simulation results. The base case modelling approach generally gives the nearest match between trial and simulation whereas simulations that include the aisles constriction over-predict. As noted in the E17 trial evacuations, the exclusion of the desks and chairs did not make any appreciable difference to the total evacuation time so the base case simulation is probably a reasonable representation of this scenario. A hand calculation using no pre-movement delay, a flow of 1.33 occupants/s per metre effective width and an effective door width of $0.48 \mathrm{~m}$ gives a total evacuation time of $42 \mathrm{~s}$ for 27 occupants and $25 \mathrm{~s}$ for 16 occupants. Similar to the modelling of the primary trial evacuations, including the effect of rows (and in combination with aisles) gives a considerable over-prediction. Given the consistent over-prediction that results from the effect of rows (and in combination with aisles) these algorithms are no longer modelled in detail. 
Table 4. Lecture rooms E17 and E15 trial evacuations and EvacuatioNZ simulation results.

\begin{tabular}{|c|c|c|c|c|c|}
\hline & \multicolumn{2}{|c|}{ E17 (27 occupants) } & \multicolumn{3}{c|}{ E15 (16 occupants) } \\
\cline { 2 - 6 } & $\begin{array}{c}\text { No pre- } \\
\text { movement } \\
(\mathbf{s})\end{array}$ & $\begin{array}{c}\text { Log-normal } \\
\text { pre-movement } \\
(\mathbf{s})\end{array}$ & $\begin{array}{c}\text { No pre- } \\
\text { movement } \\
(\mathbf{s})\end{array}$ & $\begin{array}{c}\text { Log-normal } \\
\text { pre-movement } \\
(\mathbf{s})\end{array}$ & $\begin{array}{c}\text { Normal pre- } \\
\text { movement } \\
(\mathbf{s})\end{array}$ \\
\hline Trial & 28 & 70 & 21 & 34 & 44 \\
\hline Base case & $40 \pm 5$ & $72 \pm 11$ & $22 \pm 2$ & $56 \pm 10$ & $55 \pm 7$ \\
\hline Aisles & $38 \pm 4$ & $71 \pm 11$ & $23 \pm 3$ & $59 \pm 13$ & $55 \pm 5$ \\
\hline Rows & $60 \pm 3$ & $94 \pm 12$ & $41 \pm 3$ & $74 \pm 13$ & $70 \pm 6$ \\
\hline $\begin{array}{c}\text { Both aisles } \\
\text { and rows }\end{array}$ & $61 \pm 4$ & $92 \pm 11$ & $41 \pm 3$ & $74 \pm 12$ & $71 \pm 7$ \\
\hline
\end{tabular}

Figure 4 shows the mean total evacuation time from the model against the secondary trial data. Here the assessment of EvacuationZ is only based on the total evacuation time where the base cases or the cases that include the effect of the aisles are similar and EvacuatioNZ generally over-predicts. The results only show that the flows at the exits are appropriately modelled and does not necessarily demonstrate EvacuatioNZ is simulating other aspects of the trials adequately.

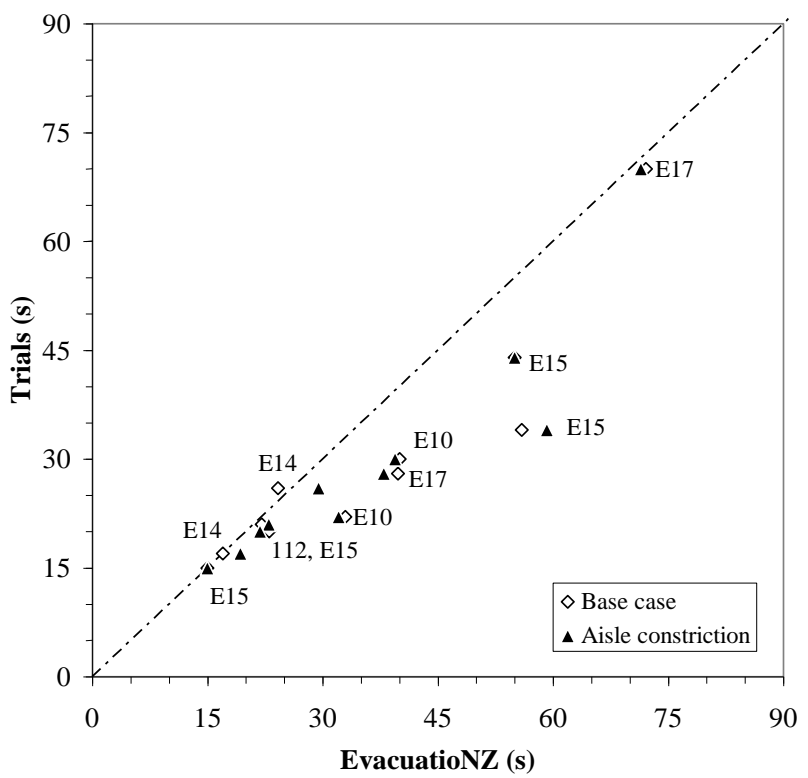

Fig. 4. Base case and aisle constriction mean total evacuation times given by EvacuatioNZ against the secondary evacuation trial data.

\section{Literature Data}

It is useful to compare EvacuatioNZ predictions with the data available in the literature as a means of assessing the model rather than only relying on data obtained by the authors. However it is found in most cases that a number of assumptions are required to adequately carry out the modelling which limits the interpretation of the results.

To model the trial described by Regan [7] occupants are proportionally distributed between each theatre based on their maximum capacity such that $\mathrm{C} 1$ has 98 people and $\mathrm{C} 2$ has 180 people. The probability of the choice of exit usage is the same as that given in the primary evacuation trials described previously. Premovement time is represented as a triangular distribution using Regan's statistics. It is assumed that the time to exit the theatre is the same as total evacuation time (i.e. no queuing at main exits). The base case simulated evacuation times are $49 \pm 7 \mathrm{~s}$ for $\mathrm{C} 1$ and $104 \pm 10 \mathrm{~s}$ for $\mathrm{C} 2$ with aisle constriction the same. These simulated times bracket the experiment result of $90 \mathrm{~s}$ and the match between the trial and simulations could be improved by adjusting a proportion of occupants in each room, the percentage of occupants using 
different exits etc. For example, using 118 occupants in $\mathrm{C} 1$ and 160 occupants in $\mathrm{C} 2$ gives mean total evacuation times of $57 \mathrm{~s}$ and $92 \mathrm{~s}$ respectively but the occupant proportion cannot really be justified on a rational basis. The modelling carried out by Olsson and Regan [8] obtained a total clearance time of the two lecture rooms as $131 \mathrm{~s}$. Ideally it would have been useful to have had more details with regard to the exact occupant distribution and exit usage.

For Kimura and Sime's [9] F lecture room simulation, based on the information given in the reference, the pre-movement time is estimated as $13 \mathrm{~s}$. The EvacuatioNZ base case gives a total evacuation time of $58 \pm 3 \mathrm{~s}$ and including the aisles gives $71 \pm 4 \mathrm{~s}$ compared with the trial result of $181 \mathrm{~s}$ such that EvacuatioNZ always significantly under-predicts result. Kimura and Sime also gave times for the first 43 people to exit through the two doors. When the number of people using each exit is fixed to the trial Fig. 5 shows that EvacuatioNZ gives quicker times to reach the exits and generally faster exit flow rates even when both aisle and row effects are included. For Kimura and Sime's [9] R lecture room the premovement time is estimated to be $2 \mathrm{~s}$. EvacuatioNZ modelling gives a base case total evacuation time of $105 \pm 2 \mathrm{~s}$ and $133 \pm 2 \mathrm{~s}$ when the effect of aisle width is included compared with trial result of $88 \mathrm{~s}$. Clearly EvacuatioNZ always over-predicts the R lecture room result even with a very low pre-movement time. Analysis of the performance of EvacuatioNZ with regard to the Kimura and Sime data is inconclusive without further details in particular regarding the pre-movement times.

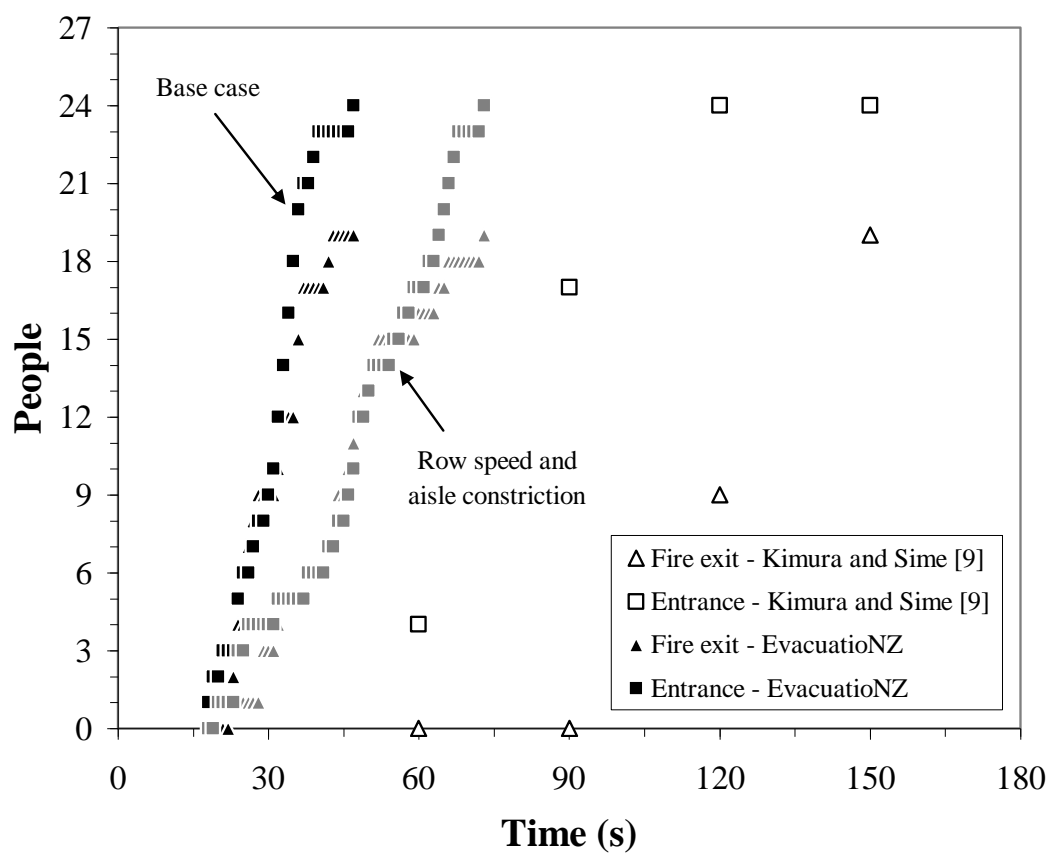

Fig. 5. Comparison between measured evacuation time for the first 43 occupants of Kimura and Sime [9] $\mathrm{F}$ lecture room and simulated times from EvacuatioNZ.

To model the theatre presented by Weckman et al. [10] the pre-movement time was assumed to be a uniform distribution between $30 \mathrm{~s}$ and $47 \mathrm{~s}$ based on the event sequence. The occupant age was estimated to be 40 years which might be typical of a theatre-going population. The last person to leave the auditorium in the trial evacuation was $217 \mathrm{~s}$ compared to the EvacuatioNZ base case of $170 \pm 9 \mathrm{~s}$ and $199 \pm 9 \mathrm{~s}$ when the aisle constriction was considered. EvacuationZ gives a reasonable (albeit under-predicted) result by including aisle effects. A pre-movement distribution that extends longer or has a non-uniform shape could have been used to model the trial evacuation but it is difficult to justify what that distribution might be and it would be longer than the 0-30 s used in Weckman et al.'s modelling exercises.

The trial evacuation given by $\mathrm{Li}$ and Chow [3] was modelled in EvacuatioNZ without including any premovement time (similar to simulations conducted by $\mathrm{Li}$ and Chow). The base case scenario gave a total evacuation time of $99 \pm 10 \mathrm{~s}$ and the same result was obtained by including the effect aisles since the final exit was narrower than the aisle width. Clearly EvacuatioNZ over-predicts the total evacuation time when 
compared to the $66.5 \mathrm{~s}$ obtained in the trial but the simulated exit flow rate is similar to trial data (Fig. 6). $\mathrm{Li}$ and Chow simulated the trial using buildingEXODUS and Spatial-Grid Evacuation Model (SGEM) and applied two mean flow rates of 1.323 and 1.242 occupants/s per metre width. They obtained total evacuation times of 59-63 s from SGEM and 73-79 s from buildingEXODUS depending of the flow rate and variations in the initial locations of occupants. In comparison a hand calculation using a flow rate of 1.33 occupants/s per metre effective width and effective door width of $0.6 \mathrm{~m}$ gives a total evacuation time of $103 \mathrm{~s}$ which is similar to EvacuatioNZ as might be expected.

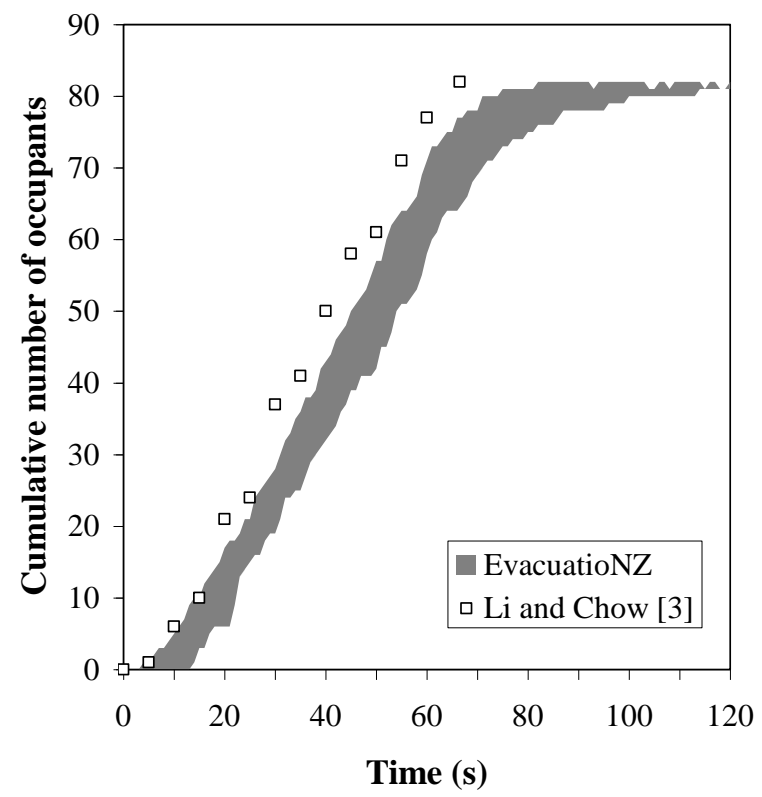

Fig. 6. Comparison between measured evacuation time from Li and Chow [3] and range of maximum and minimum simulated times from EvacuatioNZ simulations.

In order to model the Tsubuka pavilion the dimensions of the space were taken as $25 \mathrm{~m}$ by $23 \mathrm{~m}$ (the same as used by Gwynne et al. [4]) and the occupant load was taken to be 500 (again the same as Gwynne et al.) with an average age assumed to be 40 . No pre-movement time was included in the simulation and no effects of the outside weather were considered. No aisle constriction effects were modelled since no details were given by Gwynne et al. [4]. The base case EvacuatioNZ simulation gave a total evacuation time of $154 \pm 11 \mathrm{~s}$ which compares surprisingly well with the 152 to $166 \mathrm{~s}$ reported range. It is likely this match is more by good fortune rather than a measure of the accuracy of the model given the uncertainty in the source data. By creating arbitrary conditions to simulate the outside weather and using a response time distribution of 0-30 s Gwynne et al. obtained total evacuation times from 143.7 to $150.7 \mathrm{~s}$ using buildingEXODUS.

The trial evacuation presented by Zhang et al. [11] was modelled in EvacuatioNZ with a lognormal premovement (mean, $11 \mathrm{~s}$; standard deviation, $7 \mathrm{~s}$; lower limit, $0.4 \mathrm{~s}$; upper limit, $24 \mathrm{~s}$ ). Using the algorithm that accounts for the aisles, the simulated total evacuation time was $69 \pm 5 \mathrm{~s}$ as compared with the $37 \mathrm{~s}$ trial evacuation result. Zhang et al. obtained an average door flow rate of approximately 1.60 occupants/s per metre width with peak values up to approximately 2.00 occupants/s per metre width compared with the 1.33 occupants/s per metre EvacuatioNZ default. As shown in Fig. 7, modelling using a 1.60 occupants/s per metre width specific flow reduces the simulated mean time to $58 \mathrm{~s}$ but still does not wholly account for the discrepancy between the model and the trial evacuation mainly as a result of the longer delay given by EvacuatioNZ before people begin to flow through the exit. A hand calculation using a flow rate of 1.33 occupants/s per metre width and effective door width of $0.8 \mathrm{~m}$ gives a total evacuation time of $56 \mathrm{~s}$ suggesting a maximum likely hand calculation value of $80 \mathrm{~s}$ if the upper limit of the pre-movement distribution is included. 


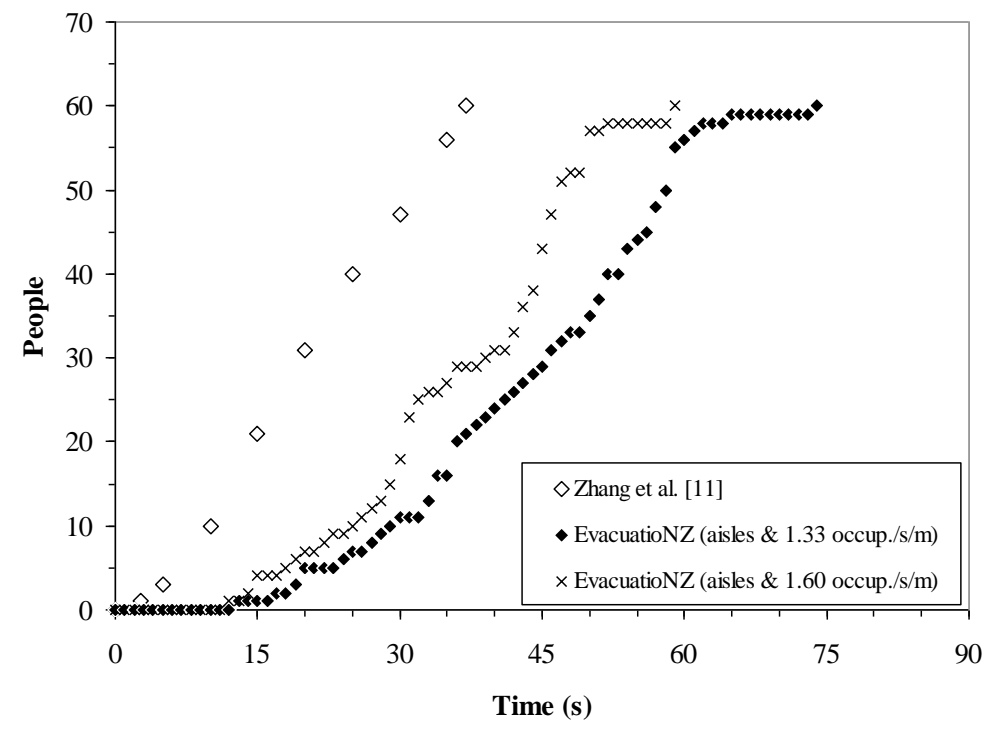

Fig. 7. Comparison between measured evacuation time from Zhang et al. [11] and typical simulated times from EvacuatioNZ.

Figure 8 shows mean simulated evacuation times using EvacuatioNZ against the measured evacuation times from the literature sources. When compared to the measured data EvacuatioNZ gives mixed results but some of the differences could be because of the assumptions necessary when specific information is not available. Overall it might be argued that using an algorithm that accounts for the aisle constriction gives a 'reasonable' outcome.

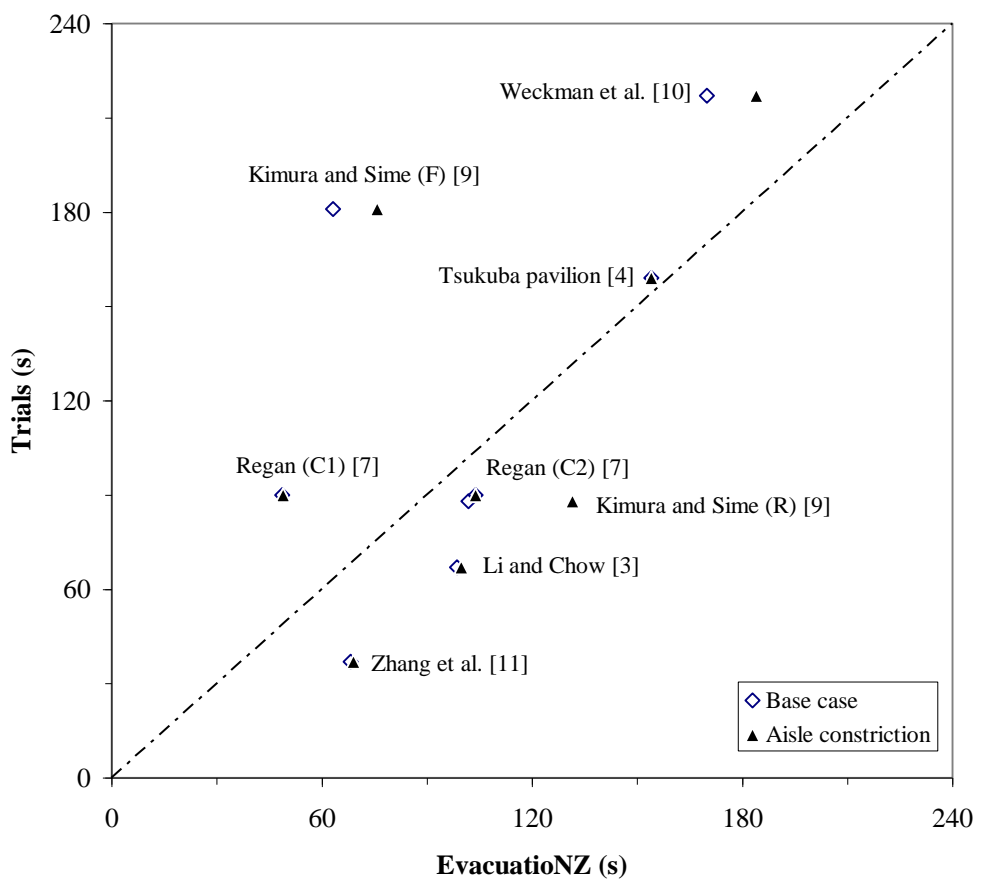

Fig. 8. Comparison of mean simulated evacuation times using EvacuatioNZ with data from the literature.

\section{CONCLUSIONS}

A network type evacuation model cannot handle detailed positional aspects of occupants in the lecture room space but can only be expected to do an acceptable job of modelling such a room type in a larger 
building simulation. Given the relative simplicity of the modelling approach used in EvacuatioNZ it can give reasonable total evacuation times and exit flows for lecture theatre type spaces where the 'best' algorithm is to use the constriction effect of aisles where appropriate.

Although the movement reduction along rows is a potential particular aspect of lecture type rooms it is noted that there are quite conflicting values for the movement speed along rows up to values that are essentially close to free movement. In this paper the value given by Predtechenskii and Milinskii [2] has been used which is the lowest of those cited and if values suggested by Gwynne et al [4] had been selected there probably would have been insignificant changes to the overall evacuation times. It would seem that for lecture rooms that have a higher population density then it is likely that the pre-movement times of people at the ends of rows is more critical than any reduction in movement speed. This queuing effect was noted in the primary trial evacuations presented in this paper. Any speed reduction long rows might therefore be more significant for sparsely populated lecture rooms. Although the effect of speed reduction could be an area of future investigation it is important not to get too focussed on one detailed aspect of a network type model such as EvacuatioNZ given the wider assumptions inherent in the model.

Figure 9 shows a comparison of all of the predictions presented in this paper against the trial evacuation results where deviations from the equality line typically exhibit conservative values. Non-conservative outliers are partly as a result of insufficient information on the trial evacuation and assumptions necessary to obtain a result from the model.

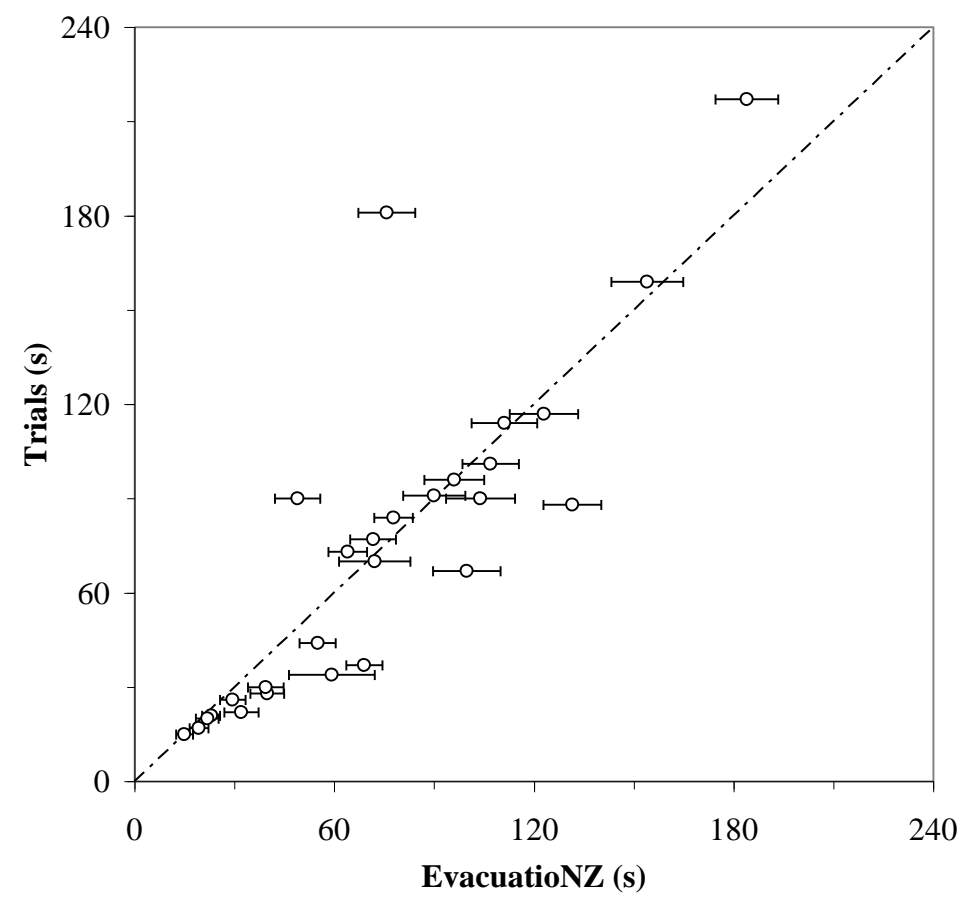

Fig. 9. Summary of EvacuatioNZ simulated total evacuation times (mean and one standard deviation) against trial evacuation results.

Using a hand calculation door flow rate for selected data sets gives results similar to EvacuatioNZ as might be expected since the model is based on the same equations. Evacuation models such as EvacuatioNZ are a useful tool to aid in the advance of simple design methods that are useful for the practising fire engineer.

\section{ACKNOWLEDGEMENTS}

The authors wish to thank Anthony Ng, Daniel Ho, James McBryde, Keryn Goble, Kevin Yu, Terrance Chuo and Wei-Li Tsai for their help in collecting data from the primary trial evacuations. The fire engineering programme at the University of Canterbury is supported by the New Zealand Fire Service Commission. 


\section{REFERENCES}

[1] Kuligowski, E.D., "Review of 28 Egress Models," Workshop on Building Occupant Movement during Fire Emergencies, June 10-11, 2004, Gaithersburg, MD, (Eds: Peacock, R.D., Kuligowski, E.D.), 2005, pp. 68-90.

[2] Predentechenskii, V.M., and Milinskii, A.I., Planning for Foot Traffic Flow in Buildings, Amerind Publishing Company, Inc., New Delhi, India, 1978, p. 240.

[3] Li,J., and Chow, W.K., (2000-2001) Numerical Studies on Evacuation Pattern in a Lecture Hall, Journal of Applied Fire Science 10(3): 265-276, http://dx.doi.org/10.2190/R8LA-JHL7-YGK7$\underline{8 \mathrm{RKJ}}$

[4] Gwynne, S., Galea, E.R., Lawrence, P.J., Owen, M., and Filippidis, L., (1997-1998) A Systematic Comparison of Model Predictions Produced by the buildingEXODUS Evacuation Model and the Tsubuka Pavilion Evacuation Data, Journal of Applied Fire Science 7(3): 235-266.

[5] Fire Safety and Evacuation of Buildings Regulations, SR 2006/123, Department of Internal Affairs, Wellington, New Zealand, 2006.

[6] Xiang, X.P., "Predicting Evacuation Time from Lecture Theatre Type Rooms," Master of Engineering in Fire Engineering Thesis, University of Canterbury, New Zealand, 2007.

[7] Regan, M.A., "Fire Alarm Information and Building Pre-movement Times," MSc Thesis, University of Canterbury, New Zealand, 1998.

[8] Olsson, P.Å., and Regan, M.A., (2001) A Comparison Between Actual and Predicted Evacuation Times, Safety Science 38(2): 139-145, http://dx.doi.org/10.1016/S0925-7535(00)00064-3

[9] Kimura, M., and Sime, J.D., 1989. Exit Choice Behaviour During the Evacuation of Two Lecture Theatres," Fire Safety Science 2: 541-550. http://dx.doi.org/10.3801/IAFSS.FSS.2-541

[10] Weckman, H., Lehtimäki, S., and Männikkö, S., (1999) Evacuation of a Theatre: Exercise vs Calculations, Fire and Materials 23(6): 357-361, http://dx.doi.org/10.1002/(SICI)10991018(199911/12)23:6<357::AID-FAM711>3.0.CO;2-5

[11] Zhang, J., Song, W., and Xu, X., (2008) Experiment and Multi-grid Modeling of Evacuation from a Classroom, Physica A 387(23): 5901-5909, http://dx.doi.org/10.1016/j.physa.2008.06.030

[12] Gwynne, S.M.V., and Rosenbaum, E.R., "Employing the Hydraulic Model in Assessing Emergency Movement," Section 3, Chapter 13, The SFPE Handbook of Fire Protection Engineering $\left(4^{\text {th }} e d\right)$, DiNenno P.J. (ed.), National Fire Protection Association, Quincy, MA, USA, 2008, p.3/373-3/396.

[13] Proulx, G., "Evacuation time," Section 3, Chapter 12, The SFPE Handbook of Fire Protection Engineering ( $\left.4^{\text {th }} e d\right)$, DiNenno P.J. (ed.), National Fire Protection Association, Quincy, MA, USA, 2008, p.3/355-3/372.

[14] Spearpoint, M.J., (2009) Comparative Verification Exercises on a Probabilistic Network Model for Building Evacuation, Journal of Fire Sciences 27(5): 409-430, http://dx.doi.org/ $\underline{10.1177 / 0734904109105373}$

[15] Ko, S.Y., Spearpoint, M.J., and Teo, A., (2007) Trial Evacuation of an Industrial Premises and Evacuation Model Comparison, Fire Safety Journal 42(2): 91-105, http://dx.doi.org/ 10.1016/j.firesaf.2006.07.001

[16] Smith, R.A., (1995) Density, Velocity and Flow Relationships for Closely Packed Crowds, Safety Science 18(4): 321-327, http://dx.doi.org/10.1016/0925-7535(94)00051-4

[17] Lord, J., Meacham, B., Moore, A., Fahy, R., Proulx, G., "Guide for Evaluating the Predictive Capabilities of Computer Egress Models," NIST GCR 06-886, National Institute of Standards and Technology, Gaithersburg, MD, USA, 2005, 102 p. 